\section{Feeding Tube Use in Italian Nursing Homes: The Role of Cultural Factors}

To the Editor:

Many patients in the advanced phase of dementia have eating and swallowing disorders, with resulting weight loss and recurrent aspiration. ${ }^{1}$ Although feeding tube (FT) use has no demonstrable health benefits and could also be associated with increased risks and discomfort, physicians often apply this practice in the hope of delaying death or enhancing quality of life. ${ }^{2}$ The decision to use FTs in the severely demented is not homogeneously accepted and varies considerably within states and countries. ${ }^{1,3} \mathrm{~A}$ recent nationwide study across US nursing homes (NHs) found a 10-fold difference in the state's rate of FT use, with some requiring a written advance directive to forgo FT placement while others did not. ${ }^{1}$ More recently, Mitchell and colleagues ${ }^{4}$ reported an average US national use of $34 \%$, with several factors, including organisational (for-profit facility, urban area, having more than 100 beds, and lacking a special dementia care unit), demographic (younger age, male sex, divorced marital status, lack of advanced directives, a recent decline in functional status, and no diagnosis of Alzheimer's disease), and ethnic or racial (non-white race) factors, being strongly related to its use. Other studies showed that NH staff often turn to FT use irrespective of a poor (less than 6 months) survival prognosis ${ }^{5}$ because financial incentives are paid to nursing facilities. ${ }^{6}$

Although studies about FT prevalence are scanty in Europe, its use seems to be significantly less prevalent than in the US. ${ }^{7}$ We wish to contribute to this topic with our own results on two surveys carried out at different times in one $\mathrm{NH}$ in the province of Brescia and in $13 \mathrm{NHs}$ in the province of Cremona (Lombardia Region, Northern Italy).The first survey began in 1997 and had a 3-year follow-up. A total of 124 patients were included, of whom $59(47.6 \%)$ had a Mini Mental State Examination (MMSE) score equal to 0, 7 (5.6\%) a MMSE score ranging from 1 to 3, $27(21.8 \%)$ a MMSE score ranging from 4 to 11 , and $31(24.2 \%)$ a MMSE score ranging from 12 to 22 . During the period of the survey, 9 patients $(7.0 \%)$ received a nasogastric tube and $3(2.3 \%)$ a percutaneous endoscopic gastrostomy. The use of these devices was more frequent in the first year (6 patients with nasogastric tube and 1 with percutaneous endoscopic gastrostomy), and decreased afterwards. At 36 months, 69 patients died, 10 of whom had FTs. No clinical factor was significantly associated with FT use, although patients with one of these devices were younger $(83.7 \pm 10.1$ vs. $86.2 \pm 7.6$ years, $P=$ $.29)$, had higher MMSE scores $(7.3 \pm 7.7$ vs. $5.9 \pm 6.8, P=$ $.50)$, lower BMI values $(19.7 \pm 8.1$ vs. $22.1 \pm 5.8, P=.19)$, higher number of diseases $(3.8 \pm 3.0$ vs. $3.3 \pm 1.8, P=.49)$, longer institutionalization $(4.9 \pm 3.1$ vs. $4.3 \pm 3.7$ years, $P=$ .16 ), and tended to be less behaviorally disturbed (neuropsychiatric inventory $=0.8 \pm 2.8$ vs. $8.3 \pm 12.5, P=.06$ ). The second survey was carried out in July 2003, focusing mainly on the $\mathrm{NH}$ organizational characteristics associated with FT use. All the NHs of our area with more than 100 beds $(n=14)$ in both provinces were considered eligible to take part to this survey. A questionnaire was sent and 13 (totalling 2501 beds) answered. On the whole, 1132 residents were demented and 1048 bedridden. Nine hundred ninety-eight $(88.1 \%)$ were aged 80 years or more, and 341 (30.0\%) were men. Among the demented, only $21(1.8 \%)$ and $33(2.9 \%)$ subjects were fed by nasogastric tube or percutaneous endoscopic gastrostomy, respectively. In six nursing homes, the global use of these devices was less than $2.0 \%$, while it ranged from $2.2 \%$ to $6.6 \%$ in the others. Clinical (ie, age, gender, bedridden status) and organizational (ie, for-profit profile, rural location, presence of a dementia special care unit, daytime presence of registered nurses and physicians, presence of physical therapist in the staff) variables were not significantly associated with FT use, except for the full-time nurses equivalent per bed-ratio which was higher at night-time $(P=.01)$ in the facilities with higher FT use. However, it is of interest that all $\mathrm{NH}$ had at least one or more full-time $(35 \mathrm{~h} / \mathrm{wk})$ staff physicians and a team of volunteers helping nurse staff in the feeding procedures for disabled.

The most relevant information from these studies is that FT use is low among Italian NHs (and significantly lower than US facilities) and that it is not associated with common clinical or facilities' characteristics. One potential explanation may depend on the fact that FT use does not receive a specific reimbursement by the national health system, and, therefore, physicians are not compelled by $\mathrm{NH}$ administrators to increase its use. However, it is likely that other factors may contribute to explain our findings. Some years ago, a policy act of the Italian National Government established the presence of a full-time physician in the $\mathrm{NH}$ teams. Within a few years, $\mathrm{NH}$ physicians achieved the cultural leadership of the staff, becoming the main "actors" of the care and assuming the responsibility of the therapeutic strategies for residents. ${ }^{8} \mathrm{NH}$ physicians routinely promote periodic meetings with all subjects involved in the care (nurse staff, volunteers, relatives), focusing on the problems related to severe dementia and on the ethical and practical meanings of the end-of-life decisions. Although $\mathrm{NH}$ physicians are sensitive to emotional needs of the relatives and also to the requests of other caregivers (including nurse staff), they do not give up their role of cultural leaders and ultimately decide the therapeutic options. Within this framework, whether to initiate FT use or to focus mainly on comfort is a problem that is discussed among all persons involved in the care, but remains a medical decision. This is of particular interest since previous studies seem to indicate that $\mathrm{NH}$ nurses and patient's relatives generally favor FT use. $^{9-11}$ In 1996, a study on 232 Italian geriatric nurses evaluated their attitude towards the use of enteral nutrition in severely demented patients, finding that a great majority of them (73.3\%) favored the use of FTs regardless of the severity of patient's mental status. ${ }^{10}$ More recently, Lubart and colleagues ${ }^{11}$ 
found that $\mathrm{NH}$ staff and patients' relatives are often ambivalent toward FT use, on the one hand believing that it is an essential procedure for delivering food and fluids for life support, but on the other hand fearing that FT use may prolong a life of suffering. In this light, it should be hypothesized that the cultural leadership of $\mathrm{NH}$ physicians may have played a critical role for counterbalancing the attitudes of nurses and relatives towards the use of FT. Another factor that may be related to low FT use in our facilities is the presence of a team of trained volunteers. The volunteers are organized in groups with the main objective oriented toward providing feeding assistance to residents unable to eat independently. Usually volunteers are influenced by a Roman Catholic background. This is not irrelevant since the Roman Catholic position on the use of artificial nutrition and hydration near the end of life is that although "there should be a presumption in favor of providing nutrition and hydration to all patients, including patients who require medically assisted nutrition and hydration," this approach is warranted only as long as it is of sufficient benefit to outweigh the burden involved to the patients. ${ }^{12,13}$ Although volunteers could not make therapeutic decisions, it should not be excluded that their religious background might influence the attitudes toward the use of invasive devices, contributing, at least indirectly, to prevent the use of nutritional artificial interventions for those who are unlikely to benefit.

The Italian attitude is certainly less aggressive than that of other (US and Netherlands) end-of-life decision approaches and, perhaps, more fatalistic. Probably, transcultural, in addition to financial and environment-specific factors, are important in the decision to use FTs. Future studies designed to compare transcultural attitudes and understand the role of the different subjects involved in the care of severely demented patients are needed to explore the basis for future interventions.

Giuseppe Bellelli, MD
Rehabilitation and Aged Care
Unit (RACU)
"Ancelle della Carità" Hospital
Cremona, Italy

Giovanni B. Frisoni, MD

Laboratory of Epidemiology and

Neuroimaging

LENITEM

IRCCS San Giovanni di

Dio-FBF

Brescia, Italy

e AFaR - Associazione

Fatebenefratelli per la Ricerca

Roma, Italy

Marco Trabucchi, MD

University "Tor Vergata"

Rome, Italy

Geriatric Research Group

Brescia, Italy

\section{REFERENCES}

1. Teno JM, Mor V, DeSilva D, et al. Use of feeding tubes in nursing home residents with severe cognitive impairment. JAMA 2002;287:3211-3212.

2. Finucane TE, Christmas C, Travis $K$. Tube feeding in patients with advanced dementia: A review of the evidence. JAMA 1999;282;13651370 .

3. Mitchell SL, Kiely DK. A cross-national comparison of institutionalized tube-fed older persons. J Am Med Dir Assoc 2001;2:10-14.

4. Mitchell SL, Teno JM, Roy J, et al. Clinical and organizational factors associated with feeding tube use among nursing home residents with advanced cognitive impairment. JAMA 2003;290:73-80.

5. Mitchell SL, Kiely DK, Hamel MB. Dying with advanced dementia in the nursing home. Arch Intern Med 2004;164:321-326.

6. Mitchell SL, Buchanan JL, Littlehale S, Hamel MB. Tube-feeding versus hand-feeding nursing home residents with advanced dementia: A cost comparison. J Am Med Dir Assoc 2004;5:S22-S29.

7. Pfitzenmeyer P, Manckoundia P, Mischis-Troussard C, et al. Enteral nutrition in French institutionalized patients: A multicentric study. J Nutr Health Aging 2002;6:301-305.

8. Bellelli G, Frisoni GB, Barbisoni P, et al. The management of adverse clinical events in nursing home: A 1-year survey study. J Am Geriatr Soc 2001;49:915-925.

9. Kaiser-Jones J. The use of nasogastric feeding tubes in nursing homes: Patient, family and health care provider perspectives. Gerontologist 1990;30:469-479.

10. Zanetti O, Bianchetti A, Zanetti E, et al. Geriatric nurses' attitudes towards the use of nasogastric feeding-tubes in demented patients. Int J Ger Psychiatry 1996;11:1111-1116.

11. Lubart E, Leibovitz A, Habot B. Attitudes of relatives and nursing staff toward tuboenteral feeding in severely demented patients. Am J Alzheimers Dis Other Dement 2004;19:31-34.

12. National Conference of Catholic, Bishops. Ethical and religious directives for Catholic health care services. Washington, DC: US Catholic Conference, 1995.

13. Gillick MR. Rethinking the role of tube feeding in patients with advanced dementia. N Engl J Med 2000;342:206-210.

DOI: 10.1016/j.jamda.2004.12.014

\section{The Free Lunch and the Literature}

To the Editor:

It was a refreshing change to read something extolling the virtues of a free lunch at medical meetings. ${ }^{1}$ The literature is otherwise replete with articles that deprecate sponsored meals. ${ }^{2,3}$ As the authors aptly pointed out, most of these negative opinions emanate from academic sources where the circumstances are different from long-term care facilities, or refer to lavish meals (with gifts, entertainment, or resort lodging). I have also encountered a study whose recommendations were not supported by its findings. ${ }^{4}$

One study reported "a dramatic increase" in a drug's prescribing following a meeting sponsored by its manufacturer, and cautioned prescribers about "acting on (such) data." ${ }^{4}$ However, the study contained nothing to epidemiologically link the meeting to the prescribing increase (like smoking and cancer). ${ }^{5} \mathrm{I}$ highlighted this problem in a letter asking, "Was the increase in the prescribing of the sponsor's drug significantly greater for prescribers who attended the meeting vs. those who did not?"6 The study's authors replied, "The increase in prescribing among those who attended was $460 \%$ vs. $370 \%$ among those who did not." This "dramatic" prescribing increase even among nonat- 